\title{
El método de investigación en Francis Bacon
}

\author{
Magdalena Vexler Talledo \\ Departamento Académico de filosofía
}

El "método" y el conjunto de problemas que giran alrededor de él, constituyó uno de los principales temas de reflexión de muchos filósofos modernos. El hecho de que el criterio de autoridad que había servido como sustento del conocimiento en la Edad Media había comenzado a perder legitimidad, hizo que el hombre buscara otrofundamento que justificara y diera seguridad al conocimiento y lo encontró en la forma como éste se obtiene. El método se erige así en la garantía de ta verdad de los conocimientos obtenidos.

Francis Bacon (1561-1626) fue uno-de los pensadores que criticando el método imperante en la escolástica: el silogismo, propone y difunde la aplicación de un nuevo método y si bien no hay unamimidad en la valoración de sus aportes al desarrollo dega nuevaleiencia,es indudable que muchas de sus propuestas fueron recogidas por filósofos y científicos posteriores.

Aún en la actualidad, muchas de las categorías básicas de los métodos de investigación científica, contienen la impronta de Bacon, quien al mismo tiempo que propone un método crea una serie de metáforas que se han convertido en vocabulario común de la ciencia y la metodología tales como "saber es poder", "hipótesis previas", "experimento crucial", etc.

Tratar del método en Bacon requiere necesariamente considerar su concepción filosófica en general, y la concepción que poseía del conocimiento en particular. 


\section{LOS IDOLOS O 'IDOLAS'}

El hombre posee, según Bacon, una serie de ideas previas o prejuicios que impiden que éste tenga un conocimiento correcto de la naturaleza y que él denomina 'idolas'o ídolos. Frente al conocimiento deformado, prematuro y temerario que proporcionan estos 'idolas', se debe dar una verdadera interpretación de la naturaleza:

Para hacer comprender bien nuestros pensamientos, damos a esta nociones racionales que se transportan al estudio de la naturaleza, el nombre de prenociones de la naturaleza (porque son modos de entender temerarios y prematuros), y a la ciencia que deriva de la experiencia por legítima vía, el nombre de Interpretación de la Naturaleza ${ }^{1}$

\section{CLASES DE IDOLAS}

Las prenociones o prejuicios, que impiden tener un correcto conocimiento de la naturaleza son de cuatro clases:

Hay cuatro especies de ídolos que llenan el espíritu humano. Para hacerlos inteligibles, los designamos con los siguientes nombres: la primera especie de ídolos, es la de la tribu; la segunda, los ídolos de la cavérna; $9 a$ tercera, los ídolos delforo; la cuarta, los ídolos del teatro ${ }^{2}$.

\section{Idolos de la Tribu}

Estos ídolos o 'idolas', tienen su fundamento en la misma naturaleza humana y son generales a todo el género humano o tribu. Estos ídolos se originan en la insuficiencia de los sentidos. Aunque se piense que obtenemos un conocimiento exacto de las cosas, esto no es así, afirma Bacon:

\footnotetext{
1 Bacon, Novum Organum, Lib. I, XXVI, Ed. Porrúa, México 1980, p. 40.

2 Ibid., Lib I, XXXIX, p. 42.
} 
Se afirma erróneamente que el sentido humano es la medida de las cosas; muy al contrario, todas las percepciones tanto de los sentidos como del espíritu, tiene más relación con nosotros que con la naturaleza. El entendimiento humano es con respecto a las cosas, como un espejo infiel, que, recibiendo sus rayos, mezcla su propia naturaleza a la de ellos, y de esta suerte los desvía y corrompe ${ }^{3}$.

Estos errores, según Bacon, tienen su origen o en la esencia humana o en sus prejuicios o en su inestabilidad, en las pasiones o en la limitación de los sentidos.

\section{Idolos de la Caverna}

Estos ídolos o 'idolas' tienen su fundamento en la naturaleza individual de cada sujeto, y están vinculados con el tipo de educación que cada uno recibe, así como también con las experiencias particulares de cada individuo:

...todo hombre, independientemente de los errores comunes a todo el género humano, lleva en sí cierta caverna en que la luz de la naturaleza se quiebra y es corrompida, sea a causa de disposiciones naturales particulares de cada uno, sea en virtud de la educación y del comerciol coon dos-otros hombres, sea a consecuencia de las lecturas y de la autoridad de aquéllos a quienes cada uno reverencia y admira, ya sea en razon de las impresiones.

\section{Idolos del Foro}

Estos errores provienen del lenguaje. Bacon considera que muchas veces creemos que el pensamiento se impone al lenguaje, pero esto no siempre es así, pues muchas veces es el lenguaje el que se impone a nuestro entendimiento y pensamiento:

Los hombres se comunican entre sí por el lenguaje; pero el sentido de las palabras se regula por el concepto del vulgo. He aquí por qué

3 Ibíd., Lib. I, XLI, p. 42.

4 Ibíd., Lib I, XLII, p. 42. 
la inteligencia, a la que deplorablemente se impone una lengua mal constituida, se siente importunada de extraña maneras.

Los ídolos o 'idolas' del foro son de dos tipos: son nombres de cosas que no existen como por ejemplo: fortuna, primer móvil, orbes planetarios, etc. o son nombres de cosas que existen pero están mal determinadas como por ejemplo: lo húmedo, lo ligero, lo blando, etc.

\section{Idolos del teatro}

Estos errores son producidos por los sistemas filosóficos o por las malas demostraciones:

...llamámosles ídolos del teatro, porque cuantas filosofías hay hasta la fecha inventadas y acreditadas, son, según nosotros, otras tantas piezas creadas y representadas cada una de las que contiene un mundo imaginario y teatrals.

CRÍTICA

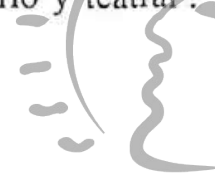

Bacon sostiene que para poder instaurar una nueva ciencia es necesario realizar primero una etapa destructiva, en la que incluye tres tipos de crítica: "Jorge Puccinelli Converso"

...la parte destructiva de nuestra instauración ...comprende tres críticas: crítica de la razón humana y abandonada a sí misma, crítica de las demostraciones, y crítica de las teorías o de las filosofías y doctrinas admitidas hasta hoy?

\section{Crítica de la Filosofía}

Bacon tiene una posición crítica tanto de la filosofía antigua, como de la Filosofía Medieval.

5 Ibíd., Lib I, XLIII, p. 42.

6 Ibíd., Lib XLIV, p. 43.

7 Ibid., Lib I, CXV, p. 77. 
Considera Bacon, que la filosofía, en general, carece de experiencia y de conocimientos de historia natural, basándose en datos muy restringidos:

la filosofía descansa sobre una base excesivamente estrecha de experiencia y de historia natural, y sus conclusiones derivan de datos legítimamente (idem) demasiado restringidos ${ }^{8}$.

Para Bacon, las denominadas por él, falsas filosofías se reducen a tres: la sofística, la empírica y la supersticiosa.

\section{La Filosofía Sofística}

Para Bacon, la filosofía sofística es aquella que ha corrompido la filosofía natural por su dialéctica, y ha construido al mundo con sus categorías. Esta filosofía, dice Bacon, se ha preocupado más de darle un revestimiento lógico a sus ideas que de penetrar en la realidad:

Siempre han atendido más a dar cierto aparato de lógica a sus respuestas y dar al espíritu algo de positivo en los términos, que de penetrar en la realidad?

Bacon sitúa erróneamente en este tipg de filosofía a Aristóteles, y considera que si bien algunas de las obras de este filosofo se encuentran llenos de hechos, él ha procedido estableciendo primero los principios generales, para después hacer de la experiencia una esclava de estos principios abstractos.

Había comenzado, Aristóteles por establecer principios generales, sin consultar la experiencia y fundar legítimamente sobre ella los principios, y después de haber decretado a su antojo las leyes de la naturaleza, hizo de la experiencia la esclava violentada de sus sistema; de manera que a este título, merece aún mas reproches que sus sectarios modernos (los filósofos escolásticos) que han olvidado la experiencia por completo $^{10}$.

8 Ibíd., Lib I, LXII, p. 49.

? Ibíd., Lib I, LXIII, p. 49.

10 Ibíd., Lib I, LXIII, pp. 49-50. 
Para Bacon, las ideas de otros filósofos griegos contienen más conocimientos sobre filosofía natural y contienen en germen una referencia a la experiencia:

En efecto; las homeomerías de Anáxagoras, los átomos de Leucipo y Demócrito, el cielo y la tierra de Parménides, el odio y la amistad de Empédocles, la resolución de los cuerpos en el sistema indiferente del fuego, y su vuelta al estado de densidad, de Heráclito, revelan su filosofía natural, y tienen cierto sabor de experiencia y realidad, mientras que la física de Aristóteles, no contiene de ordinario otra cosa que su dialéctica ${ }^{11}$.

\section{La Filosofía Empírica}

Para Bacon, esta filosofía se ha basado en un número reducido de experimentos. Aquí sitúa a los químicos ya Gilbert. Bacon advierte el peligro que significa esta corriente al firmar.

...no deja de ser muy importante ponerse en guardia contra tales sistemas, pues prevemos y auguramos ya que, si el espíritu humano excitado por nuestros consejos, seriamente se vuelve hacia la experiencia, despidiéndose de las doctrinas sofísticas, entonces por su precipitacion, por su atraccion prematura y el salto, o mejor dicho, el vuelo por el que se efevará a las leyes generales y a los principios de las cosas, se le ofrecerá peligro constante de caer en ese género de sistema ${ }^{12}$.

\section{La Filosofia Supersticiosa}

Esta filosofía, sostiene Bacon, esta corrompida por la superstición e invadida por la teología. Esta filosofía está considerada por Bacon como más peligrosa que la filosofía empírica, porque engaña al espíritu:

\footnotetext{
$"$ Ibíd., Lib I, LXIII, p. 49.

12 Ibíd,, Lib I, LXIV, p. 50.
} 
La filosofía sofística es batalladora, aprisiona al espíritu en sus lazos; pero esa otra filosofía, hinchada de imaginación, y que se asemeja a la poesía, engaña más al espíritu ${ }^{13}$.

Bacon, sitúa en este tipo de filosofía a Pitágoras, así como a Platón. Igualmente, considera que están en este tipo de filosofía todos los filósofos que consideran las causas finales y las causas primeras sin considerar las causas medias. Igualmente, Bacon incluye en esta filosofía a algunos modernos que toman, en forma literal lo que está contenido en la Biblia, por ejemplo el Génesis.

Estos tres tipos de filosofía se refieren a la filosofía griega, principalmente. Pero, las críticas a la filosofía también se extienden a la Filosofía Medieval como una expresión de la filosofía aristotélica, si como a la filosofía natural que se cultiva en la época del propio Bacon.

\title{
La Filosofía Escolástica
}

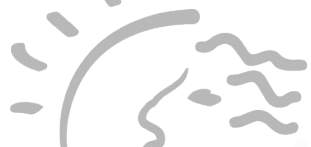

Esta filosofía, afirmaba Bacon, se caracteriza porque se basaba, no en la evidencia de lo real, sino en un sinnumero de refutaciones y objeciones que se iban multiplicando cada vez más. Estos defectos se deben, según Bacon a lo restringido de sus furentes como a da falta de observación

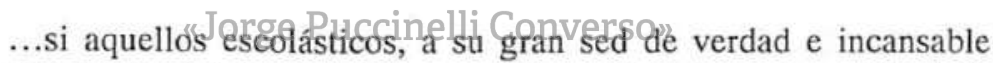
trabajo del intelecto hubieran unido variedad y universalidad de lectura y observación, habrían contribuido con las grandes luces de su experiencia a la enseñanza y al conocimiento . Mas, tal como se muestran, los escolásticos son, en verdad, grandes y feroces partidarios del mantenimiento de la oscuridad ${ }^{14}$.
\end{abstract}

\section{La Filosofía Natural}

Bacon, considera que en la filosofía natural, también se encuentra una serie de ideas equivocada, por ejemplo:

13 Ibíd., Lib I, LXV, p. 50.

14 Bacon, Francis, Del Adelanto y Progreso de la Ciencia, Ed. Lautaro, Bs. As., p. 131. 
-La consideración de que los cuerpos naturales están compuestos de átomos. Esta idea deriva, según Bacon, de considerar que los cuerpos naturales son similares a las máquinas.

El humano espíritu adquiere falsas ideas al ver lo que lo que antecede en las artes mecánicas, en las que los cuerpos frecuentemente se transforman por composición y reparación, y se imagina que algo semejante se verifica en las operaciones de la naturaleza. De ahí se ha originado la ficción de los elementos y de su concurso para componer los cuerpos naturales ${ }^{15}$.

-Otro de los errores de la filosofía natural, de acuerdo a Bacon, es el de considerar sólo los principios pasivos de donde se originan los hechos y no los principios activos por los cuales se originan estos hechos:

Otro inconveniente mayor resulta aún de que se contempla e investiga los principios pasivos y no los principios activos, por los cuales, los hechos se realizan. Los primeros, en efecto, son buenos para los discursos; los segundos para las operaciones ${ }^{16}$.

En este sentido, dice Bacon, se realizan una serie de distinciones vulgares que no contribuyen a tener un conocimiento adecuado de la naturaleza porque

\section{Biblioteca de Letras}

Nos hacen 'cofmprender bien liel hasta dónde, pero no el cómo ni de que fuente ${ }^{17}$.

-Otro de los inconvenientes de estas filosofías, afirma Bacon, radica en que éstas se ocupan de los primeros principios y de los más remotos extremos de la naturaleza y no de las causas intermedias que son las que más utilidad proporcionan y brindan más recursos para realizar las operaciones. Esto, no contribuye a aumentar las riquezas del hombre que, según Bacon, es la finalidad del conocimiento:

\footnotetext{
is Bacon, Novum Organum, Ob. cit., Lib I, LXVI, p. 51.

16 Ibíd., Lib I, LXVI, p. 51.

17 Ibíd., Lib I, LXVI, p. 51.
} 
No es tampoco pequeño inconveniente no ocuparse en las filosofías más que en investigar y determinar los primeros principios, y en cierto modo los más remotos extremos de la naturaleza; siendo así que toda la utilidad y los recursos para las operaciones, estriba en el conocimiento de las causas intermedias $^{18}$.

Bacon advierte, también, contra lo que él denomina los excesos de los filósofos con relación al fundamento de la certidumbre y las reglas de la duda. Estos excesos son de dos clases, los que deciden fácilmente y los que han introducido la duda:

Hay un doble exceso; el de los que deciden fácilmente y hacen dogmáticas y magistrales las ciencias, y el de los que han introducido la acatalepsia y un examen indefinido y sin término. El primero rebaja la inteligencia; el segundo la enerva ${ }^{19}$.

Bacon considera a Aristóteles como una de los representantes del primer caso y a Platón como representante del segundo caso.

Crítica del silogismo

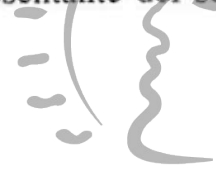

Al igual que Bacon critica-los sistemas filosóficos, también hace una crítica al método todavía predominante en su época: el silogismo. Bacon considera que el silogiśmo sôlo sifve para pefpeturar êrores y no para encontrar nuevos conocimientos que puedan mejorar la vida:

La lógica en uso es más propia para conservar y perpetuar los errores que se dan en las nociones vulgares que para descubrir la verdad; de modo que es más perjudicial que útil ${ }^{20}$.

Bacon considera que el silogismo es incapaz de llegar a conocer lo propio de la naturaleza, pues no llega a penetrar en la realidad de las cosas.

\footnotetext{
18 Ibíd., Lib I, LXVII, p. 52.

19 Ibid., Lib I, LXVII, p. 52.

20 Ibíd., Lib I, XII, p. 38.
} 
No se pide al silogismo los principios de la ciencia; en vano se le pide las leyes intermedias, porque es incapaz de abarcar la naturaleza en su sutilidad, liga al espíritu, pero no a las cosas ${ }^{21}$.

Bacon sostiene que las leyes generales carecen de validez porque han sido deducidas del silogismo o están basadas en las nociones de la inducción vulgar:

El silogismo se compone de proposiciones, las proposiciones de términos; los términos no tienen otro valor que el de las nociones. He aquí porque si las nociones (y éste es punto fundamental), son confusas y debidas a una abstracción precipitada, lo que sobre ellas se edifica carece de solidez; no tenemos, pues, confianza más que en una legitima inducción ${ }^{22}$.

Del mismo modo, Bacon considera que tanto las nociones generales que provienen de la física como de la lógica no tienen nada de exactas, al igual que las que están contenidas en los términos debido a que son producto de la imaginación o están mal definidos.

NECESIDAD DE UN NUEVO MÉTODO

Biblioteca de Ietras

Para poder penetrar en los secretos de Ja naturaleza, Bacon considera la necesidad de utilizar un nuevo método:

...para penetrar en los secretos de la naturaleza, es preciso que, tanto las nociones como los principios, sean arrancados de la realidad por un método más cierto y más seguro, y que el espíritu emplee en todo mejores procedimientos ${ }^{23}$.

\footnotetext{
21 Ibíd., Lib. I, XIII, p. 38.

22 Ibíd, Lib I, XV, p. 18.

23 Ibíd., Lib I, XVIII, p. 39.
} 


\section{CARÁCTER DEL CONOCIMIENTO}

La necesidad de establecer un nuevo método deriva de la concepción que tiene Bacon del conocimiento. Al igual que Descartes, Bacon reclama un conocimiento operativo, es decir un conocimiento práctico que pueda convertir al hombre en amo y señor de la naturaleza:

La ciencia del hombre es la medida de su potencia, porque ignorar la causa es no poder producir el efecto. No se vence a la naturaleza sino obedeciéndola ${ }^{24}$.

La finalidad del conocimiento no es otra que la de dotar al hombre de recursos nuevos que le hagan la vida más fácil:

El objeto y fin último de las ciencias, han sido, pues, mal establecidos por los hombres; pero aun cuando los hubieren fijado bien, el método era erróneo e impracticable ${ }^{25}$.

\section{VÍAS DE LA INVESTIGACIÓN Y DEL CONOCIMIENTO}

Bacon sostiene que la investigación se puede realizar a través de dos vías.Estas dos vías partenede la experiencia, pero la diferencia esta en la forma como se llega a los principios o axiomas:

"Jorge Puccinelli Converso"

1. Una de las vías parte de los hechos y sin considerar etapas intermedias se remonta a los principios,

2. La segunda vía, partiendo, también, de la experiencia llega a los principios pasando por las leyes:

$\mathrm{Ni}$ hay ni puede haber más que dos vías para la investigación y descubrimiento de la verdad: una que partiendo de la experiencia y de los hechos, se remonta en seguida a los principios más generales (axiomas supremos), y en virtud de esos principios que ad-

\footnotetext{
24 Ibíd., Lib I, III, p. 37.

2s Ibíd., Lib I, LXXXI, p. 60.
} 
quieren una autoridad incontestable, juzga y establece las leyes secundarias (axiomas medios), cuya vía es la que ahora se sigue, y otra, que de la experiencia y de los hechos induce las leyes, elevándose progresivamente y sin sacudidas hasta los principios más generales que alcanza en último término. Esta es la verdadera vía, pero jamás ha sido puesto en evidencia ${ }^{26}$.

\section{Finalidad de la Ciencia}

Mientras que la finalidad de la práctica consiste en producir nuevas propiedades en un determinado cuerpo, la finalidad de la ciencia consiste en descubrir a partir de una propiedad dada, la forma o diferencia verdadera :

Descubrir de una propiedad dada la forma o la diferencia verdadera, o la naturaleza naturante, o la fuente de conservación (éstos son los términos que mejor indican lo que queremos designar), es el oficio y objeto de la ciencia humana ${ }^{27}$.

Causas de la utilización del método incorrecto

Bacon se extraña de que durante muchg tiempo, el hombre no haya utilizado un método basado en la abservación y la experimentación.

Las razones que Bacon señala para que sucediera esto son:

- El recurrir sólo a las opiniones vertidas por otros cuando se quiere realizar una investigación y a base de éstas realizar sus propias meditaciones.

- Utilizar la dialéctica que no sirve para la invención, sino sólo para establecer principios muy generales.

26 Ibíd., Lib I, XIX, p. 39.

27 Ibíd., Lib II, I, p. 87. 
- El recurrir a la experiencia, pero sin un verdadero método que guíe la observación y la experiencia, convirtiéndose en un mero tanteo que no conduce a nada.

- El prejuicio de considerar que el hombre se rebaja si se dedica a realizar sus estudios en base a la experiencia y a los datos que proporcionan los sentidos.

Un prejuicio muy antiguo, pero lleno de arrogancia y de peligro.. consiste en que la majestad del espíritu humano es rebajada si por largo tiempo se encierra en la experiencia y en el estudio de los hechos que los sentidos perciben en el mundo material ${ }^{28}$.

- El excesivo respeto y reverencia por la antigüedad y por la autoridad de los considerados grandes filósofos de quienes se aceptaban sus opiniones sin someterlas a análisis.

En este sentido, Bacon expresa una idea muy moderna, la de considerar que los verdaderos sabios son los de surépoca pues en ese momento la humanidad ha avanzado más en el tiempo.

...nuestro tiempo es el anciano-del mundo, y se encuentra rico en observación y experiencia"29.

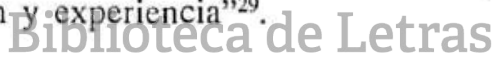

- El desarrollo de úna cieneia dogmaticica y'rácionalista que no ha servido para el desarrollo de las artes, sino más bien para que los inventos y descubrimientos dejen de producirse.

- El trasladar a la naturaleza los defectos propios de los hombres, entre ellos el considerar que una dificultad individual es una dificultad propia de la naturaleza.

- Realizar estudios limitados, no expandiendo la investigación a diversos aspectos de la naturaleza de manera que pueda descubrir de modo más fácil aquello que en otro aspecto se presenta difícil de descubrir:

28 Ibíd., Lib I, LXXXIII, p. 61.

29 Ibíd., Lib I, LXXXIV, p. 62. 
...fenómenos que pasan por secretos, son en otros objetos evidentes y están sometidos a la ley común; no se les comprenderá jamás si los hombres concentran todos sus experimentos y sus meditaciones sobre los primeros objetos ${ }^{30}$.

- El temor de la superstición y de la religión a los estudios de la naturaleza, por considerar que pueden contribuir a que el hombre pierda la moderación y llegue a excesos:

...no hay que sorprenderse que los progresos de la filosofía natural hayan sido contenidos, cuando la religión, que tanto poder ejerce sobre el espíritu de los hombres, se ha visto inclinada y arrastrada contra ella por el celo ignorante y torpe de algunos ${ }^{31}$.

La falta de libertad y creatividad existente en las escuelas, academias y colegios, que mediante el sistema rígido y cerrado que imponen a los estudiosos, dejan de ser lugares de sabiduría para convertirse en sitios donde la investigación es una tareá solitaria no apoyada por el sistema.

La falta de reconocimiento del trabajo de los investigadores por parte de los que deben hacerlo:

El cultivo des las ciencias y el precio de ese cultivo, no están en una misma mano; tas inteligencias elevadas son las que hacen progresar

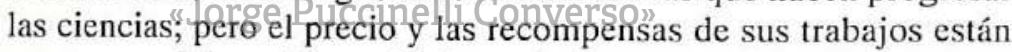
en manos del pueblo y de los príncipes, que, salvo muy raras excepciones, son medianamente instruidos ${ }^{32}$.

- La presunción que poseen los hombres de que es imposible conocer la naturaleza debido a que la vida es breve o que los errores que se pueden cometer, por la insuficiencia de los sentidos, son muchos, etc.

Por todo esto es que Bacon recomienda no recurrir a las bibliotecas, donde se encuentra inmensa variedad de libros que no hacen sino repetir lo

\footnotetext{
30 Ibíd., Lib I, LXXXVIII, p. 65.

31 Ibíd., Lib I, LXXXIX, p. 67.

32 Ibíd., Lib I, XCI, p. 67.
} 
que ya otros han dicho. Igualmente, considera que no se debe recurrir a la alquimia, ni a la magia natural ni sobrenatural, pues si bien la alquimia ha prestado verdaderos servicios a los hombres porque han realizado descubrimientos, éstos han sido conseguidos por el trabajo implicado en ella y no por el fin que perseguían, de igual modo la magia natural si bien ha contribuido a enriquecer la práctica con algunas de sus obras contiene una serie de conjeturas absurdas que no contribuye al conocimiento correcto de la naturaleza.

esas novedades son de tal género, que se las puede admirar, pero no servirse de ellas ${ }^{33}$.

Igualmente, si existe la magia sobrenatural, no sería de utilidad porque se basa en la superstición.

\section{EL VERDADERO MÉTODO}

Bacon considera que el no haber progresado en la adquisición de conocimientos se debe a que los hombres no han seguido el verdadero método de investigación y han consumido sus fuerzas por el camino equivocado:

...si los hombres han consumido sus fuerzas en una dirección que a ninguna parte podía conducirles, dedúcese de ello que no es en

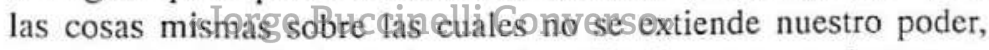
donde existe la dificultad, sino en el espíritu humano y en la manera cómo se le ha ejercitado, cosa a la que ciertamente le podemos poner remedio ${ }^{34}$.

Bacon considera que el método adecuado es el método experimental, formado por experiencias ordenadas y reguladas:

El verdadero método experimental, al contario, ante todo, enciende la antorcha, y a su luz muestra seguidamente el camino, comenzando por una experiencia bien regulada y profunda, que no sale de

33 Ibíd., Lib I, LXXXV, p. 62.

34 Ibíd., Lib I, XCIV, p. 69. 
sus límites, en la que no se desliza el error. De esa experiencia, induce leyes generales, y recíprocamente de esas leyes generales bien establecidas, experiencias nuevas ${ }^{35}$.

Los que aplican este método proceden como las abejas que recogen sus materiales en las flores de los jardines y de los campos pero los transforma por sí mismos, a diferencia de los empíricos que proceden como las hormigas que sólo saben recoger y gastar, como también se diferencian de los racionalistas que actúan como las arañas que sacan todo de sí mismos. Los que aplican el verdadero método ocupan el término medio entre los empiristas y los dogmáticos.

Por todo esto, Bacon considera que es necesario destruir todo lo que hasta ahora se he hecho para instaurar una nueva ciencia basada en un nuevo método.

La experiencia

Bacon considera que en épocas anteriores sólo se ha tenido en cuenta los rumores de la experiencia, no la verdadera experiencia.

Bacon sostiene que no se ha aplicado una verdadera experiencia porque se la ha realizado de manera negligente y vaga sin tener en cuenta la medida, ni la cantidad:

\section{Blblioteca ae Letras}

\section{"Jorge Puccinelli Converso»}

Nuestra historia natural nada investiga según las verdaderas reglas, ni comprueba, ni cuenta, ni pesa, ni mide nada. Así todo lo que es inestimado y vago en la observación, conviértese en inexacto y falso en la ley general ${ }^{36}$.

\section{Dos Historias Naturales}

Bacon sostiene que hay dos Historias Naturales: una teórica, hecha para ella misma, y otra Historia Natural práctica, para ser aplicada en las artes

\footnotetext{
35 Ibíd., Lib I, LXXXII, p. 60.

${ }_{36}$ Ibíd., Lib I, XCVIII, p. 71.
} 
(técnica). Es en ésta donde se podrá constatar si las leyes y conocimientos obtenidos funcionan o no:

...los secretos de la naturaleza se manifiestan mejor bajo el hierro y el fuego de las artes, que en el curso tranquilo de sus ordinarias operaciones $^{37}$.

\section{Características del Nuevo Método}

El nuevo método propuesto por Bacon, afirma el propio autor, debe reunir los siguientes requisitos:

- Debe investigar una mayor número de experiencias y de diverso orden.

- Debe seguir un nuevo orden y otra disposición en el encadenamiento y gradación de las experiencias. La experiencia no debe ser vaga, pues en ese caso sólo constituye un tanteo.

- Debe seguir reglas ciertas y graduales:

...cuando la experimentación siga reglas ciertas y avance gradualmente en uz orden metódico, entonces se podrá esperar mayor resultado de las eienciassa. de Letras

\section{"Jorge Puccinelli Converso»}

- Debe proceder gradualmente, elevándose de lo hechos a las leyes menos elevadas y de éstas a las leyes intermedias para llegar a las leyes más elevadas:

Mucho habrá que esperar de las ciencias cuando el espíritu ascienda por la verdadera escala y por grados sucesivos, de los hechos a las leyes menos elevadas, después a las leyes medias, elevándose más y más hasta que alcance al fin las más generales de todas ${ }^{39}$.

37 Ibíd., Lib I, XCVIII, p. 70.

38 Ibíd., Lib I, C, p. 71.

39 Ibíd., Lib I. CIV, p. 72. 
- Debe basarse en experimentos que surjan de una preparación escrita previa y obedeciendo a un plan.

- Debe tener subidas y bajadas, es decir, elevarse, a las leyes generales y bajar a la práctica.

- Debe ser perfectible, en tanto pueda ir mejorando con la práctica:

Estamos también muy distantes de afirmar que nada se puede añadir a nuestros preceptos; antes al contrario, nosotros, que ponemos la fuerza de la inteligencia no en su propia virtud, pero si en el comercio con la realidad, debemos declarar que el arte de los descubrimientos puede desenvolverse con los descubrimientos mismos ${ }^{40}$.

\section{Finalidad del Nuevo Método}

Bacon nos dice que al proponer elnuevo método no tiene como objetivo fundar alguna escuela o secta filosófica alestilo de los antiguos filósofos o de los pensadores modernos. El fin del nuevo método es aumentar el poder del hombre:

Nuestro objeto, antes al contrario- es ver si podemos dar al poderío y a la grandeza del hombre fundamentos más sólidos, a la que extender sư dorminiouccinelli Converso »

Este poder que la ciencia da al hombre, de acuerdo a Bacon, es de tres tipos: la del hombre individual que quiere aumentar su poder en su país; la del conjunto de hombres que quieren acrecentar el poder de su país sobre los demás países y el poder del género humano sobre la naturaleza.

El nuevo método aun no siendo perfecto, debe servir para que la inteligencia pueda tener mayor solidez y facilidad para relacionarse con la naturaleza que es donde radica su verdadera fuerza. La inteligencia por si misma no tiene poder, necesita del método.

\footnotetext{
40 Ibíd., Lib I, CXXX, p. 85 .

4! Ibíd., Lib 1, CXVI, p. 77.
} 


\section{OBJECIONES AL NUEVO MÉTODO}

Bacon analiza las objeciones que se le podrían hacer al método propuesto que llevaría a lo que el denomina la interpretación de la naturaleza:

- No se ha fijado el verdadero objeto de la ciencia. Bacon considera que una de las críticas que se le puede hacer a su posición podría ser la de sostener que al considerar que el objetivo más importante del conocimiento es su aplicación práctica se estaría dejando de lado el verdadero objeto de la ciencia que es la contemplación de la verdad, objetivo superior y más noble que las operaciones que realiza la industria. Sin embargo, sostiene Bacon, al utilizar su método no se renuncia a este fin, pues se trata de fijar una imagen fiel del mundo tal como es en la realidad y no basada en la simple imaginación. Para lograr esta certera imagen del mundo es necesario descomponerlo:

...para llegar ahí no hay otro medio que hacer del mundo una disección y una anatomia muyexactas. Es preciso soplar sin piedad sobre esas especies de mundos y esos signos de creaciones que ineptamente ha edifícado la imaginación humana en la filosofía ${ }^{42}$

- Se repite lo que otros filósofos han dicho. Bacon considera que esto no es verdad, pues sostiene que su método es diferente al planteado por otros autores. Asi, considera que los antiguos hân aplicado el método basándose en pocos ejemplos y hechios parăemontarse a los principios sin pasar por las leyes intermedias.

-El método se aplica sólo a la naturaleza. Bacon afirma que esto no es así, pues también se puede aplicar a la lógica a la moral y a la política:

...no se dirige tan sólo a las ciencias naturales, sino a todas sin excepción, nuestro método que procede por inducción, tiene también un alcance universal ${ }^{43}$.

- El método pretende destruir la filosofía así como las ciencias y artes. Bacon, rechaza esta objeción pues él no se opone a que en la conver-

42 Ibíd., Lib I, CXXIV, p. 82.

43 Ibíd., Lib I, CXXVII, p. 82. 
sación y en el uso cotidiano de la gente se siga utilizando los antiguos procedimientos :

...no nos oponemos en modo alguno a que alimenten las discusiones, sirvan de adorno a los discursos y sean propuestas en las cátedras, presten a la vida civil la comodidad y la brevedad a ellas propia, y, en una palabra, tengan curso entre los hombres como moneda por consentimiento general ${ }^{44}$.

- El método da armas a los intentos y pasiones. Bacon considera que esta objeción no tiene sustento pues a todo puede dársele mal uso:

Otro tanto puede decirse de los bienes del mundo, el talento, el valor, las fuerzas, la belleza, las riquezas, la misma luz y otras ${ }^{45}$.

El Nuevo Método: La inducción

El nuevo método propuesto pon Bacon es el de la inducción. Sin embargo, se debe diferenciar la inducciốn propuesta por Bacon de la inducción por simple enumeración.

\section{Inducción Enumerativi iblioteca de Letras}

La inducción baconiana es diferente de Ya inducción que procede por simple enumeración llamada también inducción completa o inducción finita. Esta inducción, según expresión del propio Bacon, se caracteriza porque lleva a una conclusión sin importancia y que es fácilmente rebatible:

La inducción que procede por simple enumeración, es una cosa pueril que conduce a una conclusión precaria, que una experiencia contradictoria puede destruir y que dictamina muy a menudo acerca de un restringido número de hechos sólo sobre aquellos que por si mismos se presentan a la observación ${ }^{46}$.

\footnotetext{
44 Ibíd., Lib I, CXXVIII, p. 83.

4 Ibíd., Lib I, CXXX, p. 85.

46 Ibíd., Lib I, CX, p. 75.
} 
La inducción por simple enumeración, por tanto se caracteriza por lo siguiente:

- Se basa en un número reducido de casos.

- Sus conclusiones no son significativas.

- Fácilmente se puede encontrar un contra ejemplo que puede destruir la conclusión.

\section{OBJETIVOS DE LA INDUCCIÓN}

La inducción baconiana se puede utilizar tanto en la práctica como en la teoría: en la práctica la inducción sirve para hacer aparecer en un determinado cuerpo una o varias propiedades. En la ciencia, la inducción ha de servir para establecer la forma o naturaleza naturante.

Hacer nacer en un cuerpo dado ana o varias propiedades nuevas y revestirle de ellas (por inducción), es el oficio y el objeto de la potestad humana. Descubrir de una propiedad dada la forma o la diferencia verdadera, o la naturaleza naturante, o la fuente de la conservación (éstos son los términos que mejor indican lo que queremos designar $)^{47}$.

Aquí aparece en Bacon la distinción entre naturaleza naturante y naturaleza naturata. Según esta disfificionl, atribuiłar ofiginalmente a Averroes, la naturaleza naturante es el agente productor, es decir la causa inmanente que produce los cambios, mientras que la naturaleza naturata es el resultado. La forma en este caso está identificada con la naturaleza naturante.

Los fines de la práctica se logran transformando unos cuerpos en otros, mientras que los fines de la ciencia se logran estableciendo tanto el esquerra latente como el proceso latente, de los cuerpos.

La ciencia tiene en realidad como objeto investigar y establecer la ley. El fundamento de la práctica y de la ciencia es el establecimiento de la ley y sus modalidades.

47 Ibíd., Lib II, I, p. 87. 
Para Bacon el esquema o configuración latente de un cuerpo vendría ser la estructura de los cuerpos sin considerar el movimiento que se produce en ellos, es decir que el esquematismo latente se refiere a los cuerpos considerados estáticamente.

De acuerdo al esquematismo latente a los cuerpos se les puede considerar como:

la reunión y el agregado de diversas naturalezas simples, así el oro reúne las siguientes propiedades; ser amarillo, pesado... ${ }^{48}$.

El proceso latente se refiere a los cuerpos pero teniendo en cuenta el movimiento de los mismos. formal.

La Forma

El proceso latente prepararía a los cuerpos para que actúe la causa

Establecer la forma es èlobjetivo deda inducción, según Bacon. Partiendo de las cuatro causas establecidas por Aristóteles; causa material, causa eficiente, causa final y causa formal, Bacon considera que la causa final produce más bien perturbaciones en el hombre y las causas material y eficiente no son útiles para la ciencia tal como se han venido estudiando, porque son inestables y pasajeras:

Conocer las formas, es haber comprendido la unidad de la naturaleza en medio de las materias más desemejante, y por consiguiente, poder descubrir y producir fenómenos y operaciones hasta aquí desconocidos... Así, pues, del descubrimiento de las formas resulta una teoría verdadera y una amplia prâctica ${ }^{49}$.

\footnotetext{
48 Ibíd., Lib II,V, p. 89.

49 Ibíd., Lib II, III, p. 88.
} 
Llegar a determinar la forma significa contar con un precepto, veraz y amplio que al mismo tiempo permita llevar a la práctica una operación final.

Establecer el significado de forma en Bacon es considerado por los intérpretes del filósofo como una de las tareas más importantes, por ser un concepto básico dentro de su concepción. Sin embargo no hay unanimidad entre los que han realizado esta tarea. Para algunos autores habría ambigüedad en el uso del término o por lo menos diversos y hasta contradictorias acepciones. Este tema ha sido tratado tanto por filósofos clásicos como por autores contemporáneos:

Para Hegel:

...es difícil llegar a saber qué es lo que él entiende por causas formales, Bacon no dice en ninguna parte claramente lo que estas formas sean...Podría pensarse que entiende por ello las determinabilidades inmanentes de las cosas, las leyes de la naturaleza, en realidad las formas no son otrá cosa que las determinaciones generales ${ }^{50}$.

Para Risieri Frondizi, establecer lo que Bacon entiende por forma es una tarea importante pero a la vez difícil, ya que habría una contradicción en su uso, entendida una vecesicomiresencia de dras eqmo ley:

Una tarea "an importante como dificiliersue" debe enfrentar todo comentarista del Novum Organum es aclarar lo que entiende Bacon por forma. Importante, puesto que 'el propósito del conocimiento humano es descubrir las formas' ...y difícil ya que Bacon oscila entre diversas acepciones posibles del término ${ }^{51}$.

De acuerdo al mismo Frondizi hay distintos pasajes en el Novum Organum donde el concepto de forma puede entenderse como esencia (II, 4; II, 20, II, 13; etc) o como ley (I, 51; II, 5; II, 17). Esto plantearía el problema de si hay una incompatibilidad entre las dos acepciones, así como también si

so Hegel, G.W.E. Lecciones sobre la Historia de la Filosofia, tomo III, Sección Primera, F.C.E., 1985 ,

51 Frondizi, Risieri, en Bacon, Novum Organum, Ed. Losada, Bs. As., 1961, p. 173. 
existe ambigüedad en el uso de los dos términos o simplemente para Bacon no habría incompatibilidad entre los dos significados asignados. Para algunos autores como Fowler, y el propio Frondizi, no habría incompatibilidad entre los significados de esencia y ley.

Otro problema que plantea la interpretación del término forma en Bacon está referido a qué relación existe entre forma y causa. Algunos autores como Fowler, citado por Frondizi, asimilan el concepto de forma a la de causa, así como el concepto de naturaleza a efecto. Frondizi, sin embargo, no está de acuerdo con esta identificación:

No creemos posible interpretar la forma baconiana en el sentido de causa, entendida como antecedente que precede al fenómeno estudiado, puesto que la forma coexiste con el fenómeno, es contemporánea a él. ...A nuestro juicio la crítica revela el poco fundamento de la asimilación de la forma a la causa y de la naturaleza al efecto pues no podría pasar inadvertido a una mente como la de Bacon que causas distintas pueden producir un efecto único ${ }^{52}$.

De acuerdo a Sortais, el término forma tiene tres acepciones en Bacon:

a) En primer lugar, dice Sortais, la forma es entendida como la verdadera diferencia. Esta difereneia vendría a ser la diferencia específica, que interviene en la definición esencial cort género próximo y diferencia específica. Esta acepción está presente, cuando por ejemplo se define el calor como un movimiento expansivo, donde 'expansivo' sería la diferencia específica del género próximo movimiento.

b) En segundo lugar, continúa Sortais, la forma en Bacon debe entenderse como esencia. En este caso, la forma designaría a la cosa misma en su constitución íntima. De ese modo donde quiera que una cosa esté ahí estará su forma o esencia íntima. La esencia de la cosa es inseparable de la cosa misma:

52 lbíd., pp. 176-177.

53 Sortais, Gastón,La Filosofía Moderna, Ed. Difusión, Bs. As., 1953, p. 427. 
La forma es la causa invisible de la naturaleza o propiedad; la naturaleza es la apariencia visible que manifiesta la existencia de la forma ${ }^{53}$.

En estos dos casos, sostiene, Sortais, la forma se comporta como definición:

Porque así como una definición debe convenir a todo lo definido y sólo a ello, así la forma está presente en todos los casos en que las cosas aparece y en cada uno de ellos (inest omni, inest soli) ${ }^{54}$.

c) En tercer lugar, siempre según Sortais, el término forma significaría ley. Este sentido, de acuerdo a Sortais, sería el que preferiría Bacon.

Para Sortais, la materia y el esquematismo latente, esto es la disposición interna de las partes o elementos de que están compuestos los cuerpos, serían llevados a un estado de susceptibilidad por la causa eficiente y la causa formal:

La causa eficiente o latens processus (proceso oculto), opera en los cuerpos cambios insensibles que los predisponen a recibir tal o cual forma). Cuando se realizan las condiciones requeridas para la existencia de la forma, entonces la forma aparece, y se produce el acto puro, es decir, una naturaleza o cualidad simple ${ }^{55}$.

\section{"Jorge Puccinelli Converso"}

De acuerdo a Sortais, la acepción de ley aplicada a la forma, no es incompatible con los significados de verdadera diferencia o de esencia puesto que lo que distingue específicamente una cosa de otra también puede denominarse esencia aunque con menor exactitud. Así mismo. este autor considera que, de acuerdo a Bacon, para que la forma pueda existir es necesario que previamente la causa eficiente (latens processus) disponga de modo especial las partículas de la materia en armonía con la forma. De acuerdo a esto, dice Sortais:

54 Ibíd., p. 428.

5s Ibíd., p. 429. 
La causa material y la causa eficiente concurren, pues de manera insensible y oculta, para preparar el camino a la forma ${ }^{56}$.

En resumen, dice Sortais:

...la forma es la ley general según la cual se producen y se manifiestan las naturalezas o cualidades sensibles (actos puros) en todos los cuerpos individuales ${ }^{57}$.

\section{Forma y Causa Formal Aristotélica}

Otro de los problemas importantes dentro de la filosofía baconiana y que es de gran significado para la interpretación del método que él propone, es el de poder determinar si la forma que es el objetivo básico de la investigación científica corresponde a la causa formal aristotélica.

Para Bacon la causa final no sirve para la ciencia porque sólo sirve para estudiar la acciones del hombre:

Pero dista tanto la causa final de servir a las ciencias, que más bien las corrompe, a menos que se estudie las acciones del hombre ${ }^{58}$.

Igualmente, Bacon considera que fas causas materiales y eficientes son inestables y por tanto no servirian para ensanchar los límites de la ciencia y de la industria, que según Bacon, tienen otro fundamento y éste es el de la forma como ya se ha indicado.

¿Significa esto que la forma se identifica con la causa formal Aristotélica?

Para Laura Benitez:

...la forma no es esencia o forma sustancial, a la manera de Aristóteles,...Nada más erróneo para Bacon que confundir las formas

\footnotetext{
s6 Ibíd., p. 430.

57 Ibíd., p. 430.

58 Bacon, Novum Organum, Ob. cit,. Lib II, I, p. 87.
} 
con las esencias en vista de que lo que se busca no es un término metafísico, abstracto y remoto, sino la verdadera constitución de los particulares. Al alejarse de la esencia aristotélica a lo que Bacon se aproxima es a la regularidad de los procesos que se ponen en consideración...Descubrir la regularidad en lo que aparece, en los diversos casos de una naturaleza estudiada, como el calor o cualquier otra, encontrar el patrón de su dinamismo en los fenómenos dados, eso es indagar la forma o ley ${ }^{59}$.

Para Abbagnano, la forma baconiana coincidiría con la forma aristotélica. Para este autor no existiría ambigüedad en el significado de la forma tal coma la entiende Bacon:

No es... justo acusar a Bacon (como se ha hecho tantas veces) de ambigüedad en el significado que él atribuye a la palabra forma. En realidad este significado es necesariamente doble en virtud de una distinción que Bacon establece claramente y considera fundamental. Es dudoso si la teoría de la forma era tan original como creía el mismo Bacon, y especialmente si se distingue suficientemente de la aristotélica ${ }^{60}$.

Para el mismo Abbagnano, la forma de la cual habla Bacon no vendría a ser otra cosa que la sustancia aristotélica, distinguiéndose sin embargo, en que la forma baconiana no se establece a traves de definiciones conceptuales sino a través de un pródesóexperfriental que negulé a determinar los elementos que constituyen la estructura interna de las cosas, esto es el esquematismo latente y por otro lado también debe determinar el proceso generador de un fenómeno, es decir establecer el proceso latente:

No hay duda de que Bacon contrapuso su concepto de forma al del aristotelismo escolástico; pero la forma, tal como fue concebida por él, como principio estático y dinámico de los cuerpos físicos, corresponde exactamente a la auténtica forma de Aristóteles, es

\footnotetext{
59 Benítez, Laura, Descartes y Bacon. Algunos Aspectos Metodológicos, en Philosophy and Phenomenological Research, Ed. Ernesto Sosa, Providence, pp. 90-91-92.

60 Abbagnano, Nicolás, Historia de la Filosofia, tomo II. Ed. Montaner y Simón, Barcelona, 1964, p. 151.
} 
decir: la sustancia, como principio del ser, del devenir y de la inteligibilidad de toda cosa real ${ }^{61}$.

De acuerdo a Sortais, en el pensamiento de Bacon las causas materiales y eficientes rigen el devenir del ente y sus cualidades, mientras las formas son las leyes permanentes, de acuerdo a las cuales el ente se constituye y queda constituido. Basa su interpretación al analizar los textos donde Bacon explica las clases de movimiento y los atribuye a la causa eficiente. Aquí las causas eficientes aparecen como inestables y cambiantes. Igualmente, en estos mismos textos aparecen las causas materiales como cambiantes, mientras que la causa formal permanece siempre la misma. Por eso, dice Sortais, Bacon denomina a las formas; leyes fundamentales, comunes, inmutables, eternas,etc. Para este mismo autor, sin embargo, Bacon no logró reunir en un sistema coordinado la participación de las causas en un fenómeno determinado:

..las ideas de Bacon sobre la constitución íntima de los cuerpos y sobre la colaboración de las causas concurrentes, todas ellas se presentan confusas, indecisas, yuxtapuestas. El reformador no logró fundirlas en un sistema coordinado ${ }^{62}$.

\section{La Ley Científica}

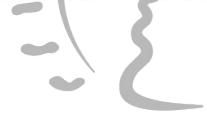

Para Bacon, la ley, es ta expresion de la forma, Tlegando a identificarlas: "Jorge Puccinelli Conver'so"

...pues hablando de la formas no queremos designar otra cosa sino las mismas leyes y las determinaciones de un acto puro que regulan y constituyen algunas propiedades simples como el calor, la luz, la gravedad en toda especie de materia y en todas las substancias que puedan admitir esa propiedad. Así, la forma del calor o la forma de la luz es absolutamente la misma cosa que la ley del calor o la ley de la luz, pues nosotros jamás hacemos abstracción de la realidad, ni perdemos de vista la práctica ${ }^{63}$.

\footnotetext{
61 Ibíd., p. 151.

62 Sortais, La Filosofia Moderna, Ob. cit., pp. 433-434.

63 Bacon, F. Novum Organum, Ob. cit., Lib II, XVII, p. 106.
} 
A través de la ley se manifiestan y se producen las cualidades sensibles de las cosas.

Con relación al significado de ley, habría que considerar a qué tipo de ley se está refiriendo Bacon:

Para Loose el uso del término ley no sería, en Bacon, igual al de otros pensadores modernos:

Si se extraen de su contexto, algunas consideraciones de Bacon sobre las 'leyes' tienen un halo moderno. Pero varias de las ideas de Bacon no son modernas. En primer lugar, Bacon concibió las leyes físicas sobre el modelo de los decretos promulgados por un poder civil. En segundo lugar, Bacon no estaba interesado en expresar las leyes en forma matemática. $\mathrm{Y}$ en tercer lugar, Bacon consideraba el universo como un conjunto de sustancias que tienen propiedades y poderes y que, mantienen relaciones unas con otras ${ }^{64}$.

Efectivamente, se ha planteado el problema del carácter de las leyes a que hace referencia Bacon. Para Adam y Brochard, citados por Sortais, la forma o ley en Bacon, tendría una referencia mecánica o matemática, con lo cual Bacon coincidiría en esto con Deseartes. Esto significaría, para ambos autores, que en Bacomexistiríateca de Letras

... una referencia mecanccinellica or matematica de las formas un presentimiento, lo vago y confuso que se quiera, de la física matemática'. De modo que la doctrina de Bacon que 'se presenta como una filosofía de la cualidad', sería en el fondo 'una filosofía de la cantidad que terminaría en el mecanicismo ${ }^{65}$.

Esta interpretación de Adam y Brochard, es calificada por el propio Sortais como muy aventurada, y se debería más bien a la tendencia de los historiadores de la ciencia a atribuir a los filósofos anteriores, conceptos que hoy nos son familiares, pero que no corresponden al propio filósofo.

64 Loose, John, Introducción Histórica a la Filosofia de la Ciencia, Alianza Editorial, Madrid, 1981 , p. 77.

65 Sortais, G. La Filosofia Moderna, Ob. cit., pp. 433-434. 


\section{ETAPAS Y REGLAS DEL MÉTODO}

Para realizar una verdadera interpretación de la naturaleza, Bacon considera dos etapas en la aplicación del método:

I) La etapa que consiste en extraer de la experiencia las leyes generales

II) La etapa en que de las leyes generales se derivan nuevas experiencias (práctica).

En cada una de estas etapas se ha de tener en cuenta una serie de reglas y preceptos.

I ) Los preceptos o reglas que se deben tener en cuenta en la primera etapa son de tres clases:

1. Los que ayudan a los sentidos.

2. Los que ayudan a la memoria.

3. Los que ayudan a la inteligencia o a la razón.

1. Los preceptos que ayudan a los sentidos. Los preceptos o reglas de los sentidos, son a su vez de dos tipos:

a) Los que sirven para suplir su insuficiencia. Para evitar la insuficiencia de los sentidos, Bacon senala una serie de auxilios que los agrupa bajo el nombre genérico de los hechos de la lámpara o de primera información y los hechos de la puerta o de la entrada.

Según Bacon, los hechos de la lámpara: "sirven para fortificar, desarrollar y rectificar la acción inmediata de los sentidos" ${ }^{\prime \prime}$.

Los hechos de la puerta son los que prestan auxilio a la acción inmediata de los sentidos, en especial a la vista entre los que se puede mencionar los lentes, los telescopios, los instrumentos como los astrolabios y similares.

\footnotetext{
66 Bacon, F. Novum Organum, Ob. cit., Lib II, XXXVIII, p. 139.
} 
b) Los que sirven para corregir las desviaciones de los sentidos, están referidos a la necesidad de tomar todas las precauciones para evitar las ilusiones de los sentidos, los cuales deben ser controlados por la experiencia.

2. Los preceptos que ayudan a la memoria.

Dentro de éstos hay dos tipos de indicaciones:

a) Constituir las historias naturales particulares, como parte de la historia natural general y

b) Formar las tablas de hechos.

Bacon recomienda formar una historia natural y experimental suficiente y exacta, la cual ha de ser el fundamento de todo estudio de la naturaleza.

Sin embargo, los fiechos que constifuyen la historia natural es tan vasta, que debe establecerse un orden, formándose las tablas y encadenamientos de hechos.

Las tablas están formadas por un conjunto de hechos que el investigador debe coleceionar sirftener todavia ninguna teoría o hipótesis previá.Jorge Puccinelli Converso»

\section{Clases de tablas}

Las tablas o colecciones de hechos son de tres clases:

Tablas de presencia, en las que se agrupan los hechos en los que se encuentra la propiedad o naturaleza que se esta investigando, por ejemplo si se está estudiando el calor se considerará todos los hechos en que esté presente esta propiedad, tales como los rayos del sol, los meteoros ígneos, la erupción de los volcanes, etc.

Tablas de ausencia, en la que aparecen los hechos similares a los registrados en las tablas de presencia, pero en los que no aparece la propiedad o fenómeno estudiado. Siguiendo con el ejemplo 
anterior, formarán parte de la tabla de ausencia los hechos en que, según Bacon, no está presente el calor: relámpagos que dan luz pero no queman, la reflexión del sol en los polos, etc.

Tablas por grados, constituidas por los hechos en que aparece en forma gradual, el fenómeno o propiedad estudiada, por ejemplo con relación al calor se considerarán los hechos en que éste aumenta, como en el movimiento en los seres vivos, la fiebre, los fenómenos de putrefacción, etc.

3. Las reglas que ayudan a la inteligencia o a la razón, son a su vez de dos tipos:

a) Las que sirven para aplicar el procedimiento inductivo y constituyen los "primeros auxilios" y

b) Las reglas o preceptos que sirven de refuerzo a la inducción.

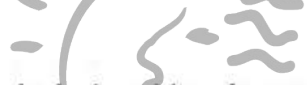

a) La aplicación de la inducción, de acuerdo a Bacon, se debe hacer a través de dos instancias:

- La exclysión de los hechos acumuladas en que no se encuentra la propiedad en estudio (el eafor por ej.).

- El estableciffientocain las propiedades" comunes en los hechos coleccionados en que se halla la propiedad estudiada.

b) Las reglas o preceptos que sirven de refuerzo a la inducción son nueve y están referidos a:

- Los hechos preferentes o privilegiados.

- Los auxiliares de la inducción.

- La rectificación de la inducción.

- La variación de las investigaciones conforme a la naturaleza del objeto.

- Las prerrogativas de la naturaleza u orden en que ha de llevarse las investigaciones.

- Los límites de las investigaciones.

- Aplicación del conocimiento a la práctica. 
- Preparación para las investigaciones.

- Escala ascendente y descendente de las leyes o axiomas.

Hechos precedentes o privilegiados

De todos los preceptos referidos a la razón, Bacon se detiene en los llamados hechos preferentes o privilegiados o "instancias prerrogativas".

Para Bacon, no todos los hechos que se dan en la naturaleza tienen el mismo valor para la investigación, existiendo entre ellos una jerarquía.

Bacon señala 27 especies de estos hechos preferentes o "instancias prerrogativas" a los que da una serie de nombres especiales tales como: 'hechos solitarios', 'hechos de migración' 'hechos clandestinos', etc. Entre estos hechos, merecen destacarse los "hechos cruciales".

Entre los hechos preferentes, colocamos en décimo cuarto lugar los hechos cruciales, tomando esta expresión de las cruces que, colocadas en el entronque de las carreteras indican los diversos caminos.

Les llamamos también hechos decisivos o jurídicos, y en ciertos casos decretos y oráculos. He aquí en que consisten: Cuando en el estudio de Piettalnaturalezacse encutenteaSel espíritu vacilante e incierto parä csaberPal cual dèi đosno descyarias naturalezas debe atribuir la causa del sujeto estudiado, en razón del concurso ordinario de esas diversas naturalezas, los hechos de la cruz demuestran que la compañía de una de esas naturalezas, en lo que al objeto estudiado se refiere, es fiel e indisoluble, mientras que la de la otra es variable y movible, lo cual resuelve la cuestión y hace admitir aquella primera naturaleza como causa, con exclusión de la otra que se deja de $1 a^{6}{ }^{67}$.

II) Los preceptos que se han de tener en cuenta en la segunda etapa no son ampliamente desarrolladas por Bacon, señalando brevemente que se debe evitar que las operaciones prácticas sean engañosas u onerosas

67 Ibíd., Lib II, XXXVI, p. 130. 
para lo cual se debe tener en cuenta los hechos matemáticos o de medida y los hechos propicios y benevolentes.

\section{APLICACIÓN DEL MÉTODO}

Después de haber confeccionado las diferentes tablas de hechos (presencia, ausencia y por grados) y de haber realizado la primera exclusión de los hechos en los que no está presente la propiedad estudiada) se debe proceder a ensayar una primera interpretación de la naturaleza por muy imperfecta que sea. A esta interpretación Bacon la denomina primera vendimia, lo que posteriormente se denominará hipótesis previa o hipótesis de trabajo.

No obstante, como la verdad sale más pronto del error que de la confusión, estimamos útil permitir al espíritu que según las tablas de primera comparecencia tal como la hemos expuesto, han sido meditadas y formadas, ensaye e intente la obra positiva de la interpretación de la naturaleza, por medio de los hechos contenidos en las tablas y de todos los que se presenten fuera de ellas.

Llamaremos a este gênero de ensayos licencia del entendimiento o interpretación imperfecta o primera vendimia ${ }^{68}$.

Esta primera hipótesis hat de seer sometida a diversas instancias, con el objeto de establecer la forâa Puleylaella naturaleza," Io cual a la vez, como ya se ha explicado, tiene como finalidad determinar el esquematismo latente (estructura de los objetos enfocados estáticamente) y el proceso latente (objetos estudiados dinámicamente).

De ese modo, de acuerdo a Bacon, se habrá aplicado el nuevo método de la inducción que permitirá al hombre realizar la verdadera interpretación de la naturaleza, convirtiendo el saber en poder.

68 Ibíd., Lib II, XX, p. 109. 


\section{IMPORTANCIA DEL MÉTODO}

Se considera que el aporte de Francia Bacon no radica solamente en haber apelado a la práctica como fundamento del conocimiento, sino en haber propuesto la inducción amplificada o científica llamada también inducción incompleta.

La inducción incompleta o baconiana, se aplica a un universo infinito y no a un universo finito como lo hace la inducción completa o por simple enumeración. Es incompleta porque al aplicarse a un universo infinito no se podrá observar todos los casos al que se aplica, sin embargo ahí radica su utilidad porque esto permitirá ampliar el conocimiento al pasar de los hechos particulares coleccionados al establecimiento de una ley.

Del mismo modo, la inducción baconiana no sólo considera los casos afirmativos donde se presenta la propiedad estudiada, el calor por ejemplo, sino que es necesario considerar los casos negativos o contra ejemplos, a través de las tablas de ausencia, dándole asi a este procedimiento un mayor margen de seguridad.

$\mathrm{Y}$ aunque al método propuesto por Bacon se le puede hacer una serie de críticas, es indudable que, como afirma Risieri Frondizi, este

método ha inspiradotas grandes metođofogías posteriores y la realidad eféctivasdePla Givestigacionterentifica ${ }^{69}$.

69 Frondizi, Risieri, Ob. cit., p. 27. 